\title{
Liquid Fuel Identification Using a Fiber Optic Sensor Based in Multimode Interference Effects (MMI)
}

\author{
Adolfo J. Rodríguez-Rodríguez, René F. Domínguez-Cruz, Daniel A. May-Arrioja \\ Centro de Investigaciones en Óptica (CIO), campus Aguascalientes, Aguascalientes, \\ Mexico \\ darrioja@cio.mx
}

\begin{abstract}
In this work, we show the fabrication of a fiber optic sensor for the liquid fuel identification which is based on multimodal interference effects (MMI). The sensor structure is formed by a no-core multimode fiber (NC-MMF) splicing between two SMF. When the NC-MMF is immersed in a liquid combustible, the conditions of effective refractive index and the effective diameter of the NC-MMF are modified. Thus and the spectral shift of an optical signal output is used as refractometer to identify every kind of fuel. This MMI sensor exhibits a sensitivity of $258.06 \mathrm{~nm} / \mathrm{RIU}$ for substances with a refraction index (RIU) from 1.318 to 1.4203 range. To test of the sensor, we use four of the most employed industrial and commercial combustibles like: methanol (M100), ethanol anhydrous (E100), gasohol (E50 to E10) and gasoline 87 octanes (G87). The sensor also provides high repeatability, reversibility and exhibit a fast and simple fabrication process. In addition, we show that the sensor response is enhancing by reducing the diameter of the NC-MMF.
\end{abstract}

Keywords: fiber optical sensor; multimodal interference effect; refractometer; liquid fuels.

\section{Introduction}

At the present, some alternatives of renewable fuel sources have been proposed as consequence of the growing demand of petroleum and green combustible. In this sense, methanol and ethanol are also used as fuel, especially when mixed with gasoline. Also the calorific value of gasoline is approximately twice the calorific value of methanol, thus making it more rentable. Some advantages of methanol as diesel combustible to vehicles are: it can be produced from renewable sources and waste of grass, bagasse sugar, litter, among others; generates less environmental pollution than fossil fuels and ordinary vehicles can use this combustible only replacing the plastic parts of fuel system (Reed et at, 1973; Olah et al, 2009).

Pure ethanol (E100) has become a very popular choice as fuel in markets such as Brazil, USA, Sweden, Thailand and others, with the advantage that combustion is less polluting and highly oxygenated. This combustible comes from sugar cane and corn as well cellulosic biomass and trees and grasses. It should be noted that the maximum permissible exposure in United States of America in air ( $40 \mathrm{~h} /$ week) is 
$1,900 \mathrm{mg} / \mathrm{m} 3$ for ethanol, $900 \mathrm{mg} / \mathrm{m} 3$ for gasoline and $260 \mathrm{mg} / \mathrm{m} 3$ for methanol. Ethanol is also employed as additive in gasoline to replace the Methyl Tert-Butyl Ether (MTBE), responsible for significant contamination of soil and groundwater. The resulting fuel mixture of ethanol and gasoline is called gasohol (West et al, 2007; Goldemberg, J. 2008).

As example, in USA there are two common blends of ethanol with gasoline named E10 and E85, which means an ethanol presence of $10 \%$ and $85 \%$ in the mixture, respectively. Since alcohol has corrosive properties, special adaptations to conventional engine vehicles that employ ordinary gasoline are required; otherwise the engine is at risk of degradation in some component materials as well in the fuel system (Ethanol fuel and cars, 2008). Therefore, the design of novel techniques and sensors that allow the accurate the detection and identification of combustible with real time monitoring is quite important to avoid any potential damage in the automotive system.

Some techniques to detect combustible and hydrocarbons are based in the use of chemiresistors (Clifford et al 2002), piezoresonance sensors systems (Kalach et al 2007), photoacoustic sensors (Freborn et al 1998), electronic fuel analyzers (Testing Kits-PetroFLAG, 2014) and infrared fuel concentration analyzers (Control Instruments Corporation 2014, Zeltex $\left.{ }^{\circledR}, 2014\right)$. Although these electronic sensors have efficient results for the measurement of liquid combustibles, oils and hydrocarbons, they may be sensitive to electromagnetic interference, exhibit a low selective drift for a particular hydrocarbon, relative high power consumption, some are expensive and unsuitable for remote operation. Optical fibers sensors are an attractive option due to their inherent characteristics such as good sensitivity, immunity to electromagnetic interference, small size, portability, low cost, high resolution, simple light coupling and the possibility for multiplexed operation (Lee, 2003, Marazuela et al, 2002). Some approaches have been investigated using Long Period Gratings (Felate et al, 2003), Fiber Bragg Gratings (Spirin et al, 1999) and incorporating sensitive polymer around the fiber (López et al, 2002; MacLean et al, 2003; Treviño et al, 2005; Sensfelder et al, 1998). However, the main inconvenient in these systems is the need for a special preparation of the fiber or the deposition of a sensitive material. A fiber sensor that can be suited for the detection and identification is the one based on multimode interference effects (MMI). MMI sensors can be high sensitive to RI changes of liquids

(Wang et al, 2006; Antonio-López et al, 2009; Wu et al, 2011; Walbaum et al, 2011; Socorro et al, 2013). In this work we demonstrate the application of a MMI optical fiber sensor as a tool to distinguish different kind of liquid combustibles. The advantages of the proposed sensor are it shown a simple fabrication, exhibits great reproducibility, reversibility and no temperature interference.

\section{Materials and Methods}

As is showed in Figure 1, the MMI structure is constructed by splicing a segment of No Core-MMF between two SMF segments. When an optical signal from the SMF segment propagates within the NC-MMF segment are excited all modes allowed within it, interfering with each other giving rise to an interference that is highly dependent on the phase relationship between modes. For a certain length L, where the phase difference is a multiple of $2 \pi$, we have the formation of self-images which 
are an exact reproduction of the input field. Therefore, by carefully selecting the length of the NC-MMF segment, light coupled through the first SMF segment, will be reproduced to the second SMF segment.

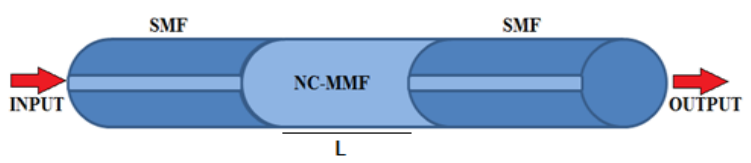

Fig. 1. Structure of the MMI element based in fiber optic.

The length of the MMF segment to which the effect of self-image is presented, for a specific wavelength can be calculated employing the following Equation 1 (Walbaum et al, 2011; Socorro et al, 2013):

$$
L=p \frac{n_{M M F} D_{M M F}^{2}}{\lambda_{0}} \quad \text { with } \quad p=0,1,2 \ldots
$$

where $n_{M M F}$ and $D_{M M F}$ are respectively the effective refractive index and the diameter of the fundamental mode of the NC-MMF segment, and $\lambda_{0}$ is the wavelength in free space. As shown in Eq. (1), the self-images are formed periodically along the NC-MMF segment, however, we want to work in every fourth image since they have minimum losses as compared to other images and the response of the MMI refractometer under a wide spectrum source will be similar to a band-pass filter as shown in Figure 2.

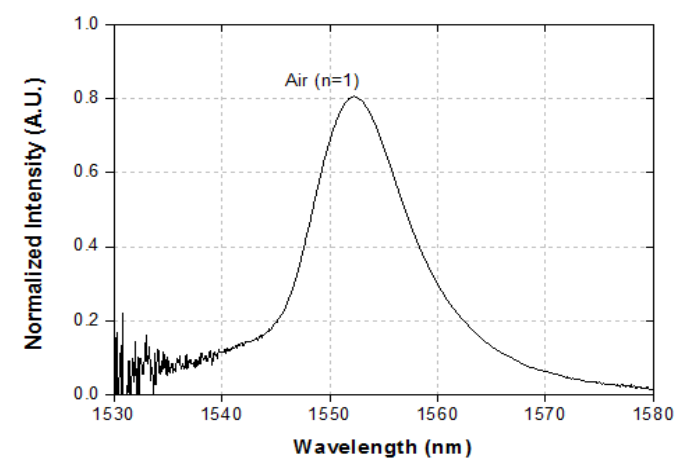

Fig. 2. Wavelength spectral response of MMI when is surrounded by air.

\subsection{Sensor Fabrication}

The NC- MMF used in our experiments is provided by Prime Optical Fiber Corporation (Japan), which is a MMF with a core diameter of $125 \mu \mathrm{m}$ without cladding and a refractive index of 1.444. Before to fabricate the MMI structures we need to obtain the exact length of the NC-MMF that will provide the desired MMI peak wavelength. According to Eq. (1), we employ a NC-MMF segment of $58.98 \mathrm{~mm}$ spliced between two segments of SMF-28 (core diameter of $125 \mu \mathrm{m}$ ) at a wavelength of $1530 \mathrm{~nm}$ for the case of the fourth self-image $\mathrm{p}=4$ using a Fujikura ${ }^{\circledR}$ splicer FSM- 
50S. The NC-MMF cladding was removed with acetone to clean any remaining residue. The final MMI sensor has a structure similar that showed in Figure 1.

\subsection{Experimental Array}

The experimental set-up for testing the MMI sensor is shown in Figure 3. A Superluminiscent Diode (SLD) centered at $1550 \mathrm{~nm}$ was connected to the input SMF of the MMI sensor, and the output SMF is then connected an optical spectrum analyzer (OSA) Agilent ${ }^{\circledR}$ 86142A to capture the transmitted spectrum. We use a chamber to fix the MMI sensor. This chamber included input and output tubes to insertion and removal of the substances. Since both MMI sensor and substances are sensitive to temperature, the measurements were performed at controlled temperature of $20^{\circ} \mathrm{C}$.

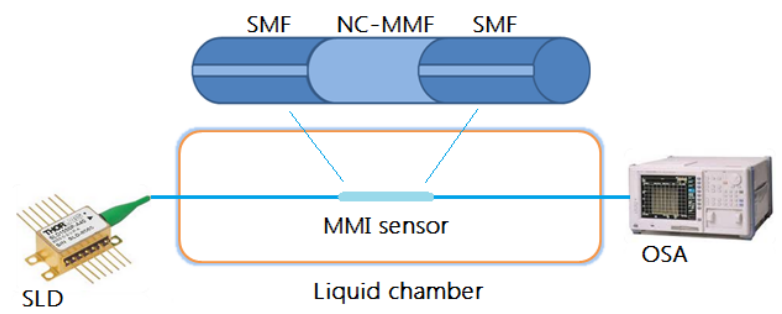

Fig. 3. Experimental set-up to identify different liquid fuels.

In order to test the utility of MMI structure designed as a refractometer, mixtures of water and glycerin

were prepared at different concentration to obtain a range of RI from 1.318 (100\% water) to 1.4204 (30\% water/70\% glycerin). Later, we cover the sensor MMI using each one of the mixtures and monitoring the wavelength shift of the peak transmitted on the structure (Figure 4) and we observe a clear resolution of MMI for each blend of water with glycerin. The next step to probe the MMI sensor was testing with different liquid fuels.

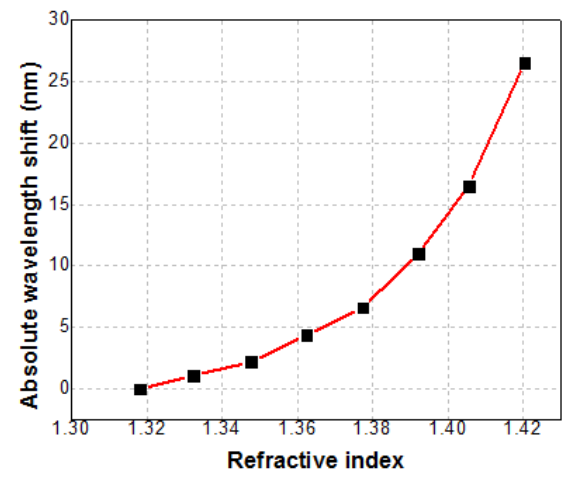

Fig. 4. MMI peak wavelength shift as a function of the RI (water and glycerin). 


\section{Results and Discussion}

In Figure 5, we present the spectrum response of the MMI device for different kinds of liquid combustibles as methanol (M100), ethanol (E100), gasohol (E50...E10) and 87 octanes gasoline (G87). In order to visualizing these results, we graph the RI estimated for each fuel with the wavelength shift peak observed considering wavelength peak in air as reference (Figure 6- black line). From this curve, the sensitivity is estimated as $258.06 \mathrm{~nm} / \mathrm{RIU}$ in 1530.2-1558.1 nm range using a NC-MMF core diameter @ 125 $\mu \mathrm{m}$.

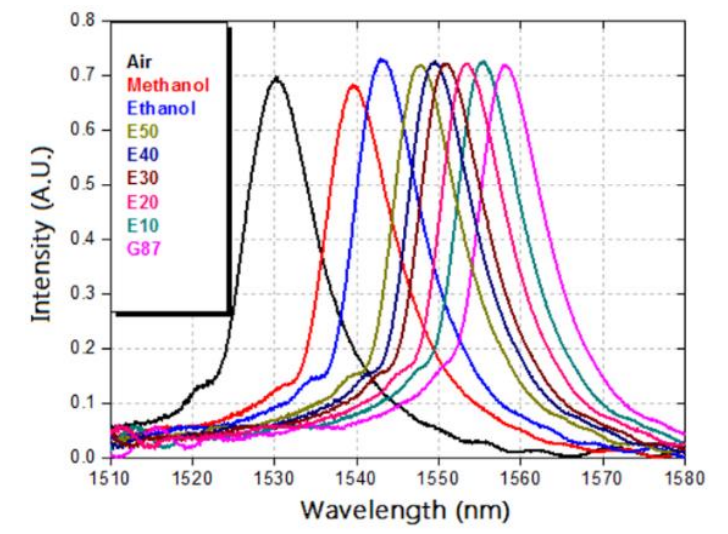

Fig. 5. Spectral response of the MMI sensor for different liquid fuels.

As shown in Figure 5 (black line) the peak wavelength in air is at $1530.2 \mathrm{~nm}$ which is very close to the design wavelength of $1530 \mathrm{~nm}$. When a sample of methanol $\left(\mathrm{n} \sim 1.318, \lambda=1530 \mathrm{~nm}, \mathrm{~T}=20^{\circ} \mathrm{C}\right)$ provided by Sigma-Aldrich ${ }^{\circledR}$ is inserted in the chamber we can observe a wavelength shift of $9.3 \mathrm{~nm}$, with the peak wavelength at $1539.5 \mathrm{~nm}$. When the sensor is exposed to anhydrous ethanol ( $\mathrm{n} \sim 1.3465, \lambda=1530 \mathrm{~nm}$, $\mathrm{T}=20^{\circ} \mathrm{C}$ ) provided by Sigma-Aldrich $®$, the MMI peak wavelength

is shifted to $1542.9 \mathrm{~nm}$. Although the shift is relatively small respect to Methanol $(\sim 3.4 \mathrm{~nm})$ it can be easily resolved by the OSA. It is important remark that we used anhydrous ethanol rather than standard ethanol, because ethanol tends to absorb water and it could modify the RI value. We prepared solutions of commercial G87 with different proportions of anhydrous ethanol. When the sensor is exposed to E50 (Gasohol prepared by EtOH 50\% / G87 50\%) ( $\mathrm{n} 1.3852, \lambda=1530 \mathrm{~nm}, \mathrm{~T}=20^{\circ} \mathrm{C}$ ), the MMI peak wavelength is shifted to $1547.7 \mathrm{~nm}$ and we can see a considerable wavelength shift ( $4.8 \mathrm{~nm}$ ) respect to ethanol.

As shown in Figure 5, the volume of anhydrous ethanol is decreased in $1 \mathrm{ml}$ and volume of G87 is increased in $1 \mathrm{ml}$ in each sample for E50 to E10. That carries to a spectral response shift to longer wavelengths. Although the wavelength shift in this blends is $\sim 1.7 \mathrm{~nm}$, (E50 to E10) the MMI sensor can identify each one of gasohol combustibles. Finally, when commercial G87 $\left(\mathrm{n} \sim 1.424, \lambda=1530 \mathrm{~nm}, \mathrm{~T}=20^{\circ} \mathrm{C}\right)$ is covering the sensor, the MMI peak wavelength is shifted to $1558.1 \mathrm{~nm}$. Although the shift is small ( $2.6 \mathrm{~nm}$ respect to E10) it can be easily resolved by the OSA. Based 
on these results we should be able to identify each one of the most useful liquids combustibles, by comparing the measured peak of each one.

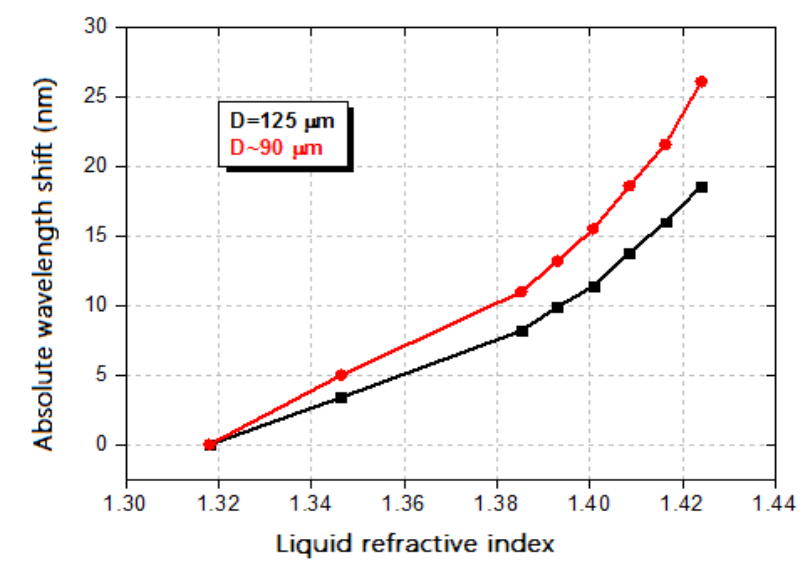

Fig. 6. Absolute wavelength shift (nm) as a function of the liquid RI for two different NC-MMF diameters.

It is well known that the sensitivity of MMI sensors can be increased by reducing the diameter of the NC-MMF (Antonio-López et al, 2009). According to Eq. (1), if the diameter of the NC-MMF is reduced then its length has to be reduced to obtain the same MMI peak wavelength. Therefore, using Eq. (1) we can calculate the required NC-MMF length for a diameter of $90 \mu \mathrm{m}$ and a peak wavelength of 1530.3 $\mathrm{nm}$, which result in a NC-MMF length of $30.57 \mathrm{~mm}$. The reduction of the NC-MMF diameter was performed by immersing the fiber in buffered oxide etching (BOE) solution, which is a mixture of hydrofluoric acid and ammonium fluoride as the buffer agent. Since the etching rate is relatively slow $(\sim 130 \mathrm{~nm} / \mathrm{min})$, we can monitor the transmitted spectrum in real time. After a total time to $135 \mathrm{~min}$ we can observe that the MMI peak wavelength is at $\lambda=1530.3 \mathrm{~nm}$. The new MMI sensor with reduced diameter was tested again for the methanol, ethanol anhydrous, gasohol (E50...E10) and G87. As shown in Figure 6, the peak wavelength shift is increased for all the liquids combustibles, but is more significant when the NC-MMF diameter is reduced.

\section{Conclusions}

We demonstrated the application of a MMI optical fiber sensor as a tool for the detection and identification of different liquid fuels. We tested MMI sensor employing four industrial and commercial combustibles like: methanol (M100), ethanol anhydrous (E100), gasohol (E50 to E10) and gasoline 87 octanes (G87). This MMI sensor exhibits a sensitivity of $258.06 \mathrm{~nm} / \mathrm{RIU}$ for substances with RI ranging from 1.318 to 1.4203 , therefore we can accurately determinate the identification of different liquids combustibles over a broad wavelength range. The advantages of the sensor are that its fabrication is straightforward, and exhibits great reproducibility and reversibility, with no significant interference against temperature or humidity. 
We also explored the feasibility of enhancing the sensor response by reducing the diameter of the NC-MMF.

Acknowledgements. We appreciate the support from the Consejo Nacional de Ciencia y Tecnología (CONACyT) under grant CB-2010/157866.

\section{References}

1. Antonio-López, J. E., López-Cortes, D., Basurto-Pensado, M. A., May-Arrioja, D. A., Sánchez-Mondragón, J. J.: All-fiber multimode interference refractometer sensor. Proc. SPIE, 7316 (2009)

2. Clifford, K., Hughes, H., Hughes, R. C.: In Situ Chemiresistor Sensor Package For Real Time Detection of Volatile Organic Compounds in Soil and Groundwater. Sensors, 2002, Vol. 2, pp. 23-24 (2009)

3. Control Instruments Corporation. Infrared Analyzers. Available at: http://www.controlinstruments.com/technologies/infrared-analyzers (2014)

4. Ethanol fuel and cars. Available at: http://interestingenergyfacts.blogspot.mx /2008/09/ethanol-fuel-and-cars.html (2015)

5. Felate, R, Müller, M., Fabris, J. L., Kalinowski, H. J.: Long Period Gratings in Standard Telecommunication Optical Fibers for Fuel Quality Control. In: Procc. XXVI ENFMC. Annals of Optics, Vol. 5 (2003)

6. Freborn, S. S., Hannigan, J., Greig, F.: A pulsed Photoacustic Instrument for the Detection of Crude Oil Concentrations in Produced Water. American Institute of Physics, Review of Scientific Instruments, Vol. 69, pp. 3948-3952 (1998)

7. Goldemberg, J.: The Brazilian biofuels industry. Biotechnology for Biofuels 2008, Available at: http://www.biotechnologyforbiofuels.com/content/1/1/6 (2014)

8. Kalach, A. V., Selemenev, V. F.: A piezoresonance sensor system for rapid evaluation of the quality of gasolines. Chem Tech Fuels Oil, Vol. 43, pp. 60-61 (2007)

9. Lee, B.: Review of the present status of optical fiber sensors. Opt. Fiber Technol, Vol. 9, pp. 57-59 (2003)

10. López, R. M., Spirin, V. V., Miridonov, S. V., Shlyagin, M. G., Beltrán, G., Kuzin, E. A.: Sensor de fibra óptica distribuido para la localización de fugas de hidrocarburo basado en mediciones de transmisión/reflexión. Revista Mexicana de Física, Vol. 48, No. 5, pp. 457462 (2002)

11. MacLean, A., Moran, C., Johnstone, W., Culshaw, B., Marsh, D., Walker, P.: Detection of hydrocarbon fuel spills using a distributed fibre optic sensor. Sens. Act. A., Vol. 109, pp. 60-67 (2003)

12. Marazuela, M. D., Moreno-Bondi, M. C.: Fiber-optic biosensors-an overview. Anal. Bioanal. Chem, 87, pp. 289-295 (2002)

13. Olah, G., Goeppert, A., Surya-Prakas, G. K.: Beyond Oil and Gas: The Metanol Economy. Second edition, Willey Vch Verlag Gmbh (2009)

14. Reed, T. B., Lerner, R. M.: Methanol: A Versatile Fuel for Immediate Use. Science, Vol. 182, pp. 4119 (1973)

15. Sensfelder, E., Bürck. J., Ache, H. J.: Characterization of a Fiber Optic System for the Distributed Measurement of Leakages in Tanks and Pipelines. Applied Spectroscopy, Vol. 52, pp. 1283-1298 (1998)

16. Socorro, A. B., Del Villar, I., Corres, J., Arregui, F. J., Matias, I. R.: Mode transition in complex refractive index coated single-mode-multimode-single-mode structure. Opt. Exp., Vol. 21, No. 10 (2013)

17. Spirin, V. V., Shlyagin, M. G., Miridonov, S. V., Mendieta-Jiménez, F. J., López- 
Gutiérrez, R. M.: Fiber Bragg grating sensor for petroleum hydrocarbon leak detection. Opt. Lass. Eng. Vol. 32, No. 5, pp. 497-503 (1999)

18. Testing Kits-PetroFLAG-Analizador cuantificación de hidrocarburos en el suelo. Available at: http://www.ambicare.com/es/productos/testes-rapidos/petroflag-analizadorcuantificacion-de-hidrocarburos-en-el-suelo (2015)

19. Treviño-Santoyo, A., Shlyagin, M. G., Mendieta, F. J., Spirin, V. V., Niño de Rivera, L.: Variación del espectro de transmitancia de una fibra óptica con recubrimiento de polímero por influencia de hidrocarburos y cambios de temperatura. Revista Mexicana de Física, Vol. 51, No. 6, pp. 600-604 (2005)

20. Wang, Q., Farrell, G.: All-fiber multimode-interference-based refractometer sensor: proposal and design. Opt. Lett., Vol. 31, pp. 317-319 (2006)

21. Walbaum, T., Fallnich, C.: Multimode interference filter tuning of a mode-locked all-fiber erbium laser. Opt. Lett., Vol. 36, pp. 2459-2461 (2011)

22. West, B. H., López, A. J., Theiss, T. J., Graves, R. L., Storey, J. M., Lewis, S. A.: Fuel Economy and Emissions of the Ethanol Optimized Saab 9-5 Biopower. Available at: https://www1.eere.energy.gov/bioenergy/pdfs/analysis_saab2007.pdf (2015)

23. Wu, Q., Semenova, Y., Wang, P., Farrel, G.: High sensitivity SMS fiber structure based refractometer-Analysis and experiment. Opt. Express, Vol. 19, pp. 7937-7944 (2011)

24. Zeltex® ZX-440-XL Near Infrared Gasoline/Diesel Fuel Analyzer. Available at: http://www.zeltex.com/desktop/zx-440xl.pdf (2015) 